\title{
Migración y masculinidades: análisis de la experiencia de un joven que emigró por amor
}

\author{
EDUARDO TORRE CANTALAPIEDRA Y CYNTHIA RODRÍGUEZ DE JESÚS
}

EDUARDO TORRE CANTALAPIEDRA

Instituto de Investigaciones Jurídicas, Universidad Nacional Autónoma de México, Ciudad de México, México e.torreca@gmail.com

Cynthia Rodríguez de Jesús Facultad de Ciencias Políticas y Sociales, Universidad Nacional Autónoma de México, Ciudad de México, México cynthia.rodriguez1985@gmail.com
Los estudios sobre las migraciones de los hombres se han enfocado en las movilidades laborales. En contraste, nuestro objetivo es detectar y analizar los malestares que experimentan en su migración los varones jóvenes que se movilizan sobre todo por motivos extraeconómicos, en relación con el referente de la masculinidad hegemónica y el estereotipo del migrante laboral, en función de sus respectivas identidades masculinas. Analizamos el relato de vida de un joven que emigró para establecer una relación de pareja y experimentó malestares derivados de sus interacciones con personas que asumían el esquema de masculinidad tradicional y los estereotipos de la migración. Además, analizamos su construcción de una identidad masculina alternativa.

PALABRAS CLAVE: masculinidades, identidad, migración internacional, masculinidad hegemónica, amor

Migration and Masculinities: The Experience of a Young Man Who Migrated for Love

Studies of men's migration have focused on labor mobilities. In contrast, our objective is to detect and analyze the discomforts-malestares-experienced by young men who migrate primarily for extra-economic reasons, in relation to the reference of hegemonic masculinity and to the stereotype of the labor migrant, and according to their respective masculine identities. To achieve this, we analyze the life story of a young man who migrated to establish a sentimental relationship. In such a migratory experience, he experienced discomforts arising from his interactions with people who assumed traditional patterns of masculinity and migration. Additionally, we analyze his construction of an alternative masculine identity.

KEYWORDS: masculinities, identity, international migration, hegemonic masculinity, love 
Como sociedad hemos oprimido mucho al hombre,

y ya le faltan habilidades como para tener libertad,

para elegir su trabajo, o en cuanto a expresar sus

sentimientos, y creo que es importante ver el espectro

de las identidades de los hombres, y darles la

flexibilidad de ser ellos mismos (entrevista con Rose.

15 de noviembre de 2015).

\section{Introducción*}

a representación tradicional del migrante mexicano a Estados Unidos ha construido un hombre en búsqueda de empleo o de mejorar sus condiciones laborales, que emigra solo o acompañado de su cónyuge. Asimismo, la emigración de los varones se ha asociado al cumplimiento del papel de proveedor económico de la familia (Rosas, 2008), considerado el mandato fundamental de la masculinidad hegemónica (MH) (Connell, 2003).

Sin embargo, no todas las migraciones de los varones encajan con esa representación ni con el tipo de migración laboral para asegurar o lograr la proveeduría. Existen otras experiencias migratorias que suponen un incumplimiento de los mandatos prescritos por la MH que no están en consonancia con los estereotipos migratorios y que llegan a generar tensiones en los entornos familiar y social del

Agradecemos muy sinceramente a Juan Guillermo Figueroa, Carolina Martínez y Rodrigo Parrini por sus consejos y comentarios en diferentes fases de la investigación. Asimismo, queremos dar las gracias a los dos dictaminadores anónimos por sus comentarios y sugerencias. Nuestra mayor gratitud a Fernando y Rose por compartir con nosotros sus experiencias y reflexiones. 
migrante, de acuerdo con los valores de género que prevalezcan en éstos, e incluso en su propia subjetividad en función de su identidad masculina, que a su vez pueden derivar en malestares (Tena, 2014). ${ }^{1}$

Nuestro objetivo es detectar y analizar los malestares que surgen en la experiencia de migración de los varones jóvenes que se movilizan para establecer una relación de pareja - los motivos económicos o laborales están en un segundo plano-, en relación con los estereotipos de la migración y con los mandatos de la MH, y en función de sus respectivas identidades masculinas.

Para el logro del objetivo propuesto, en este trabajo se recupera el relato de vida de Fernando, ${ }^{2}$ un joven mexicano cercano a los 30 años de edad, cuya experiencia de migración a Estados Unidos no concuerda con el estereotipo del inmigrante, ya que su decisión de emigrar estuvo principalmente motivada por un plan de vida confeccionado con su cónyuge, en el que la construcción de una relación de pareja fue fundamental y no la búsqueda de empleo. Esta vivencia se encuentra, en cierto modo, supeditada a ella y a las leyes migratorias que le impidieron emplearse.

Este trabajo está dividido en cuatro secciones. En la primera, se describen los elementos conceptuales y teóricos relativos a la $\mathrm{MH}$ - con especial atención en la construcción de la masculinidad en las nuevas generaciones de jóvenes - y a la relación entre migración, masculinidad y malestares. En la segunda, exponemos la metodología de la investigación, que sigue un enfoque constructivista. ${ }^{3}$ En la tercera parte, se examina la identidad masculina de Fernando en función de una serie de dimensiones: el trabajo doméstico, el deporte, las parejas, el papel de proveedor y las relaciones con sus padres a lo largo de su trayectoria de vida hasta conocer a Rose, su actual pareja. Asimismo, se contextualiza el caso con los datos generales de Fernando y su familia, y de Rose. En la cuarta parte, se indagan y analizan los malestares en la experiencia migratoria. Se siguen cuatro ejes de análisis: su propia subjetividad, las relaciones de pareja, las relaciones familiares y sus interacciones con otras personas que conoce durante la migración. También se relata la evolución de la relación de pareja, que condujo a Fernando a la experiencia migratoria. A modo de conclusión realizamos una serie de reflexiones finales sobre los hallazgos de la investigación.

\section{Aproximaciones teóricas y conceptuales}

\section{MASCULINIDADES ALTERNATIVAS FRENTE}

A LA MASCULINIDAD HEGEMÓNICA:

\section{LA CONSTRUCCIÓN DE LA(S) MASCULINIDAD(ES) EN LAS NUEVAS GENERACIONES DE JÓVENES}

Hace unas décadas, a pocos se les hubiera ocurrido preguntar qué significaba "ser un hombre". Era claro que la referencia estaba marcada por el estereotipo del varón: proveedor del hogar, capaz, confiable, ostentandor de control, con autoridad, competente, exitoso, fuerte y heterosexual (Kimmel, 1997; Kaufman, 1997; Parrini, 2000; Collin, 2007; Figueroa y Franzoni, 2011). En los últimos años, ese referente, la $\mathrm{MH}$, en ocasiones señalada como masculinidad social tradicional, se ha debilitado. Incluso diversos autores consideran que nos encontramos en un periodo de "crisis", "reestructuración" o "reposicionamiento" (Kimmel, 1997; Connell, 2003; Figueroa, 2001; Olavarría, 2003).

1 Seguimos el concepto de malestar expuesto por Tena: "implica a una persona que 'está mal' de cierta forma y en relación con algo, aunque ese 'estar mal' sea relativamente estable y en ocasiones imperceptible o indecible" (Jiménez y Tena, 2008, citado en Tena, 2014)

2 Se utilizan nombres ficticios para garantizar la confidencialidad.

3 Para más información sobre este enfoque, véase Guba y Lincoln (1994). 
Además de regular las relaciones genéricas, ${ }^{4}$ la MH puede entenderse como un referente normativo de la identidad de todos los hombres, con el que se comparan y son comparados (Olavarría, 2002). Su carácter preceptivo supone que diversos mandatos de la MH tienen que ser atendidos para llegar a "ser un hombre de verdad" (Parrini, 2000; Bonino, 2003). Asimismo, tiene un carácter persistente en el tiempo y es transferible a otras geografías, al menos en sus características fundamentales (Bonino, 2003).

El actual modelo hegemónico de masculinidad en Latinoamérica contiene una serie de mandatos que operan en el nivel subjetivo, que son difíciles de soslayar si no se quiere caer en el estigma y la marginalización (Parrini, 2000). En el contexto mexicano, varios autores señalan que la proveeduría es uno de los mandatos centrales de la MH. El trabajo remunerado proporciona recursos económicos y beneficios simbólicos, así como estatus y posición en las estructuras de poder, mientras que el desempleo coloca al hombre en la categoría social de "paria" (Gómez, 2007; Capella, 2007; Núñez, 2013).

Por otra parte, un número no desdeñable de investigaciones se ha centrado en el estudio teórico-conceptual y empírico de las masculinidades alternativas, también llamadas "nuevas masculinidades", y de otras maneras, que se alejan de la MH o la ponen en entredicho. ${ }^{5}$ En el caso mexicano, Tovar-Hernández y Rocha observan "maneras innovadoras y más equitativas de los varones para relacionarse, como son compartir responsabilidades, expresión emocional, seguridad en sí mismos, ser cooperativos socialmente y 'buscar el equilibrio de género"” (2012: 13).

Una masculinidad inclinada más al modelo tradicional — $\mathrm{MH}$ - o más alternativa será el resultado de un proceso de construcción de la masculinidad que comienza en la niñez, sigue en la adolescencia y se afianza en la juventud (Rondán, 2015: 108). En este proceso, la familia, ${ }^{6}$ la escuela, los compañeros y los medios de comunicación son esenciales como "agencias de socialización" que actúan como mediadores entre las representaciones de masculinidad existentes en una sociedad y los individuos, y de las formas de actuación que derivan de ellas (Callirgos, 2003, citado en Sancho et al., 2009). En este trabajo suponemos que conforme en las últimas décadas emergieron y se afianzaron modelos alternativos de masculinidad en México, las sucesivas generaciones pudieron adoptarlas en mayor medida.

En este sentido, existen evidencias de que las generaciones más nuevas están asociadas a patrones menos tradicionales de masculinidad. Núñez (2013), en un estudio sobre tres generaciones de hombres en Sonora, ${ }^{7}$ concluye que los entrevistados

En cuanto a las "relaciones genéricas", resulta conveniente retomar el concepto de "masculinidad hegemónica" de Connell (2003: 117): "la configuración de la práctica del género que incorpora la respuesta aceptada, en un momento específico, al problema de la legitimidad del patriarcado, lo que garantiza (o se considera que garantiza) la posición dominante de los hombres y la subordinación de las mujeres". Esta definición permite integrar la pluralidad de concepciones de lo que significa ser "un hombre de verdad" en diferentes contextos, sin perder de vista que se caracteriza por conservar la jerarquía dominante del hombre sobre la mujer.

$5 \quad$ Algunos autores discuten el papel de estas "nuevas" masculinidades como organizadoras de identidad. Mientras unos consideran que los hombres tienen capacidad para transformar el sistema de género dominante (Ponce, 2004) o afirman la existencia en las últimas décadas de una pluralidad de modelos de masculinidad (Sancho et al., 2009), para otros todavía no constituirían modelos alternativos de identidad (Bonino, 2003; Schongut, 2012).

6 Por ejemplo, la figura paterna resulta fundamental. Los hijos pueden seguir los pasos del padre o contradecirlos. Por un lado, existe lo que Connell denomina "el momento del compromiso con la masculinidad hegemónica, el momento en el cual el niño asume el proyecto de la masculinidad hegemónica como propio" (2003: 174); por el otro, los hijos pueden crear una imagen negativa del padre y rehusarse a ser como él (Badinter, 1993).

7 En la investigación fueron entrevistados 18 hombres, seis por cada generación, con un rango de edades de 73 a 83 años, 45 a 55 años y 20 a 25 años al momento de la investigación, nacidos entre 1917 y 1929, 1947 y 1956, y 1977 y 1979 , respectivamente. 
que pertenecen a la generación más joven son los que mayor capacidad tienen para reflexionar sobre su proceso de socialización, cuestionar las ideologías dominantes y entenderse como sujetos genéricos; mientras la generación más antigua es la menos capaz de enarbolar un discurso crítico al respecto. Asimismo, el autor señala que en la generación más joven es posible observar nuevos modelos de intimidad, alejados de los tradicionales.

En un estudio sobre hombres que cuidan familiares y asumen un papel diferente al de mero proveedor, Figueroa y Franzoni encuentran que los hombres pertenecientes a generaciones anteriores a 1955 parecen poseer papeles más conservadores de masculinidad, pero advierten: "hombres que pertenecen a la misma generación y nivel socioeconómico, pero con historia de vida distinta, reconstruirán su masculinidad con distintos códigos y valores" (2011: 68). La generación y las características sociodemográficas no presuponen tipos concretos de masculinidad.

En cualquier caso, aunque las nuevas generaciones de jóvenes quieran adoptar y adopten formas alternativas de ser hombre — por ejemplo, buscar una mayor equidad de género-, hasta la fecha siguen obligadas a lidiar de diversas maneras con los postulados de la omnipresente $\mathrm{MH}$.

\section{MIGRACIONES NO LABORALES, MASCULINIDADES Y MALESTARES DE LOS HOMBRES}

La representación tradicional del migrante mexicano a Estados Unidos ha sido construida como un trabajador en búsqueda de empleo o de mejorar sus condiciones laborales, que emigra solo o acompañado de su cónyuge: "pues era creencia general que la mujer tenía menos participación que el hombre, y cuando se llegó a aludir a ella fue para referirse a su papel como esposa o como presencia secundaria en el resto de la familia" (Woo, 1995: 139). En un trabajo reciente, Caicedo y Morales (2015) se aproximan a la representación social que tienen los mexicanos del “migrante”. Señalan que “el migrante construido, es una persona que, en situación de pobreza, desempleo o necesidad, decide cruzar la frontera con Estados Unidos de manera irregular en busca de oportunidades de trabajo, siendo en su trayecto o estancia vulnerable a diversos peligros, actos de discriminación y desafíos emocionales" (2015: 49).

El perfil actual de los migrantes mexicanos en Estados Unidos difiere de la representación social, pero guarda varias similitudes con ella, como era de esperarse. En 2012, los mexicanos en Estados Unidos eran $11877703,{ }^{8}$ de los cuales la mitad eran varones - 53.5\%—, dos terceras partes llegaron a ese país después de la década de 1990 - 66.4\%—, y sólo $43.4 \%$ se había graduado de preparatoria o tenía estudios superiores. La juventud de esa población migrante mexicana, 40 años en promedio, y su alta tasa de participación económica - 69.4\%, pese a la relativamente baja participación de las mujeres mexicanas - delatan el carácter eminentemente laboral de las migraciones.

Asimismo, la migración laboral de los mexicanos hacia Estados Unidos se ha entendido como una estrategia de las familias para sobrevivir. Como señala Rosas (2008), la migración de los varones se asocia a cumplir y reforzar el papel de proveedor. La autora muestra cómo, ante la crisis laboral en su lugar de origen, los hombres utilizan la migración para cumplir con esa función, que la $\mathrm{MH}$ "exige" a los varones. Perraudin (2014) incluso propone que el fortalecimiento de la masculinidad "tradicional" debe analizarse como un determinante de la migración.

Pero no todas las migraciones de los varones concuerdan con el estereotipo ni con el perfil de migrante laboral. Entre otras modalidades de

8

Las estimaciones son de Caicedo y Morales (2015) o se calcularon con base en ellos. 


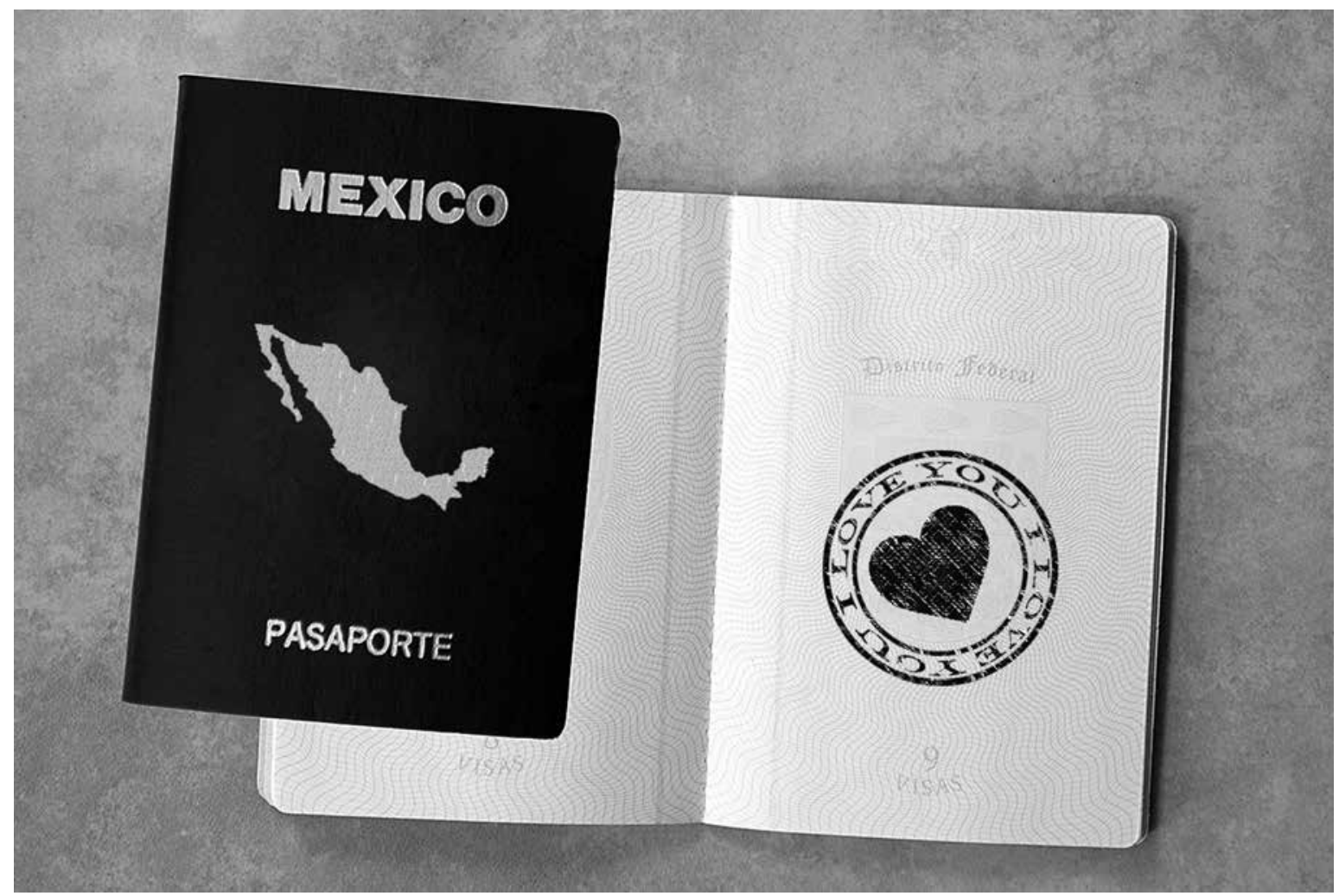

EduARdo Torre CANTALAPIEdra • Los hombre también emigran por motivos conyugales. Tijuana, 2017.

movilidad, las personas mayores emigran para reunirse con sus hijos, los niños son llevados por sus progenitores a otros países, los esposos y esposas siguen a sus cónyuges. Cuando se trata de jóvenes en edad laboral que todavía no han conformado una familia, ¿pueden ocurrir las migraciones por amor?

Varias investigaciones se refieren a las "migraciones por amor" (Sinke, 1999; King, 2002; Shah, 2006; Roca, 2007; Bodoque y Soronellas, 2010). Shah (2006) muestra que ciertas migraciones temporales de mano de obra en India no deben entenderse como sólo motivadas por razones económicas, sino por una combinación de factores, entre las que se incluye el establecimiento de relaciones amorosas. Bodoque y Soronellas utilizan el término "migrantes por amor" para referirse a "mujeres que tienen relaciones sentimentales con un hombre español y que han salido de su país para llevar a cabo un proyecto migratorio motivado por una relación sentimental que implicará la formación de una familia en el país de destino" (2010: 144).

Sinke (1999) concluye que el matrimonio y la migración siempre se han afectado el uno a la otra y que el mercado matrimonial internacional ha sido un factor importante en la decisión de emigrar de las mujeres, dado que sus oportunidades laborales son menores. Advierte que en el caso de los hombres tampoco deben perderse de vista las razones matrimoniales - incluso el amor- como un factor importante en la decisión de emigrar.

Los mercados matrimoniales internacionales y de establecimiento de relaciones de pareja están regidos por reglas y sistemas de género, como la MH, que hacen más factibles y menos criticables las 
migraciones por motivos conyugales de mujeres que de hombres en determinados contextos migratorios. Así, cuando un hombre emprende una migración de este tipo, y en su actuación no se cumplen los mandatos de la MH, como autonomía, independencia, papel proveedor, etc., ni el estereotipo del varón migrante proveedor, puede haber tensiones y conflictos que derivan en malestares en el entorno social y familiar — con su pareja ${ }^{9}$ y otros parientesy social del migrante varón, por los valores de género que prevalecen y su propia subjetividad en función de su masculinidad.

En lo referente a las relaciones con miembros de la familia y del entorno social, entendemos que las personas o grupos cuyos valores se apegan más al modelo tradicional de masculinidad tenderán a desaprobar y sancionar acciones que no se ajusten a los mandatos de la MH. Por más que el individuo rechace encarnar el esquema de la $\mathrm{MH}$, no estará exento de enfrentar malestares surgidos en la interacción con quienes sí se apegan a éste.

En la esfera individual, los malestares pueden ser causados por actuaciones que incumplen lo prescrito por la MH, según la identidad masculina que encarne el individuo. Así, cuanto más asumidos se tengan los valores de la $\mathrm{MH}$, mayor será la exigencia que se haga el propio sujeto de que sus conductas se ciñan a ella; en consecuencia, mayor será el conflicto interno que surja con acciones que los incumplan.

\section{Cuestiones metodológicas}

La metodología en este trabajo es el estudio de caso de un joven que emigra por amor y motivos conyugales para establecer una relación de pareja. El inmigrante mexicano entrevistado, Fernando, fue seleccionado de forma intencional para que no encajara en el estereotipo de inmigrante mexicano hacia Estados Unidos. Esto se logró hasta el punto en que, en ocasiones, parecía que el término inmigrante no encajaba en la descripción de su movilidad, que a la postre derivó en la migración permanente, hasta la fecha.

Para comprender los posibles malestares generados en el proceso migratorio, se realizaron tres entrevistas a Fernando durante 2015. El primer encuentro se centró en las experiencias de la infancia y la juventud, fue cuestionado sobre las múltiples dimensiones de la masculinidad. Recurrimos a los indicadores que incluyen la "matriz de rasgos prototípicos de masculinidad", desarrollada por Collin (2007), que consta de tres posibilidades de masculinidad: núcleo duro, intermedio y suave; con base en 12 indicadores: proveedor, coito, parejas, relación con los hijos, trabajo doméstico, afecto, violencia, riesgo, alcohol, espacio público, poder y deporte. La autora señala que este listado no pretende ser exhaustivo. En nuestro análisis retomamos algunos de estos indicadores por considerarlos los más adecuados para el caso de Fernando, en particular, por el contexto de su crianza y juventud. La matriz resultante se muestra en el cuadro 1.

Asimismo, para entender la construcción identitaria de Fernando, retomamos y adaptamos el concepto de identidad narrativa de McAdams: "la identidad narrativa es una historia internalizada y en evolución que nosotros mismos construimos para dar significado y sentido a la vida" (2011: 99) [la traducción es nuestra]. Esta historia de vida incluye la reconstrucción selectiva del pasado y una narración del futuro imaginado, y cambia a lo largo de la vida de la persona. En este caso, todos los elementos y dimensiones que constituyen el "relato" que narra "nuestro ser hombre" conforman la identidad narrativa masculina del individuo, que llamaremos identidad masculina.

9

Véase Rosas (2014), donde se narra cómo tras la migración internacional algunas mujeres les reclaman a sus parejas porque no tienen empleo. 
CUADRO 1. MATRIZ DE RASGOS PROTOTÍPICOS DE MASCULINIDAD

\begin{tabular}{llll} 
Rasgo & Núcleo duro & Intermedio & Blando \\
\hline Proveedor & $\begin{array}{l}\text { Principal, como } \\
\text { forma de control }\end{array}$ & Compartido & Mantenido \\
\hline Parejas & Indiscriminadas & Varias parejas & Monogamia \\
\hline Trabajo doméstico & Ninguno & $\begin{array}{l}\text { Sólo las que le } \\
\text { gustan }\end{array}$ & Igualitario \\
\hline Deportes & Fanático & Práctica familiar & Yoga o ejercicios \\
\hline
\end{tabular}

Fuente: Elaboración propia con base en Collin (2007: 92).

En la segunda entrevista se obtuvo el relato de la experiencia migratoria de Fernando en Estados Unidos, en el que se buscaron los posibles malestares de la vivencia relativos a los mandatos de la $\mathrm{MH}$ y el estereotipo del varón migrante, en función de la propia identidad masculina y la de quienes le rodean. Esto condujo a cuestionarle acerca de los significados personales de su experiencia y sus relaciones sociales, pareja, familia y otras personas que conoció durante la migración.

La tercera entrevista consistió en una conversación para obtener retroalimentación de su lectura de una versión previa de este trabajo, que recogía el análisis basado en el relato de su vida. En esta última entrevista también participó Rose, su pareja actual, lo que permitió que obtuviéramos también sus puntos de vista.

\section{La identidad masculina de Fernando al emprender el viaje}

Fernando creció en una familia extensa a la que considera conservadora, pues los ritos de la religión católica eran parte central en sus actividades. El hogar estaba compuesto por padre, madre, hermana, abuelo y abuela. Fernando caracteriza a su padre como machista, autoritario, celoso, proveedor del hogar, amante del fútbol y participativo en el trabajo doméstico. Por su parte, atribuye a su madre ser independiente, profesionista — pero que no ejerce por presión de su esposo-, vendedora exitosa de productos de belleza, inteligente, manipuladora - "pero en un sentido suave" y no peyorativo- y muy positiva. Su hermana optó por estudiar la carrera de medicina y describe a sus abuelos como profundamente religiosos.

Fernando creció en una colonia popular de la Ciudad de México, en la que las "limitaciones económicas”, los embarazos adolescentes y la baja escolaridad eran frecuentes. Por estas razones, los padres de Fernando quisieron apartarlo lo más posible de ese entorno y lo condujeron al ambiente más sano del deporte.

Una de las cuestiones más estudiadas para entender los roles de género son las familias y cómo sus miembros de ambos sexos reparten el trabajo doméstico. Por supuesto, este elemento es recuperado en la matriz de rasgos prototípicos de la masculinidad de Collin (2007). El trabajo doméstico fue un elemento importante en la organización del hogar de Fernando, pues menciona que su padre era un participante activo, sobre todo cuando se trataba de actividades que a los hombres les gustan. Además, Fernando era compelido a realizar tareas domésticas que corresponden más a las labores impuestas a las mujeres, lo que lo sitúa en el núcleo blando de la matriz:

Sí, teníamos que lavar nuestros platos después de comer, me acuerdo que mi papá se levantaba muy temprano el fin de semana, y mi papá no era 
machista en esa situación de la limpieza, sí se ponía a limpiar, nos decía: "límpiale, bárrele”, era muy autoritario [...], pero siempre sí hacía quehaceres domésticos, creo que mi cuarto siempre estaba muy limpio, siempre, o sea siempre ha estado ordenado (entrevista con Fernando, 29 de marzo de 2015).

La participación activa del padre y de Fernando en los trabajos del hogar configura una percepción positiva de los hombres hacia las actividades que han sido catalogadas como propias de las mujeres. Esta experiencia es relevante en la futura construcción del hogar de Fernando y la participación equitativa de las actividades domésticas con su pareja.

Fernando fue introducido desde temprana edad en un ámbito deportivo. Si bien su predilección por las artes marciales declinó por la preferencia de su padre hacia el fútbol.

Me gustaba el taekwondo, era mi deporte favorito, pero mi papá me sacó, dijo: “no, no, no, taekwondo ya no, fútbol”. Pues ya, como que me dio miedo enfrentar a mi papá, así de niño [...]. Realmente jugué fútbol por mi papá, que quería que fuera futbolista, pero a mí no me gustaba mucho, jugaba porque él estaba muy emocionado, pero no era mi pasión (entrevista con Fernando, 29 de marzo de 2015).

En este punto, podemos señalar que Fernando no es el fanático de los deportes que le situaría en el núcleo duro de la masculinidad en el rasgo de deportes. Sin embargo, dada la importancia que llega a desempeñar el fútbol en la socialización de los varones (véase, por ejemplo, Rondán, 2015), puede destacarse que hay un cierto elemento de reproducción social de la identidad masculina hacia lo hegemónico en el hecho de que se le imponga la preferencia por ese deporte considerado de hombres de manera tradicional.

En la dimensión de parejas, Fernando se inclinaba hacia el núcleo intermedio, pues su experiencia

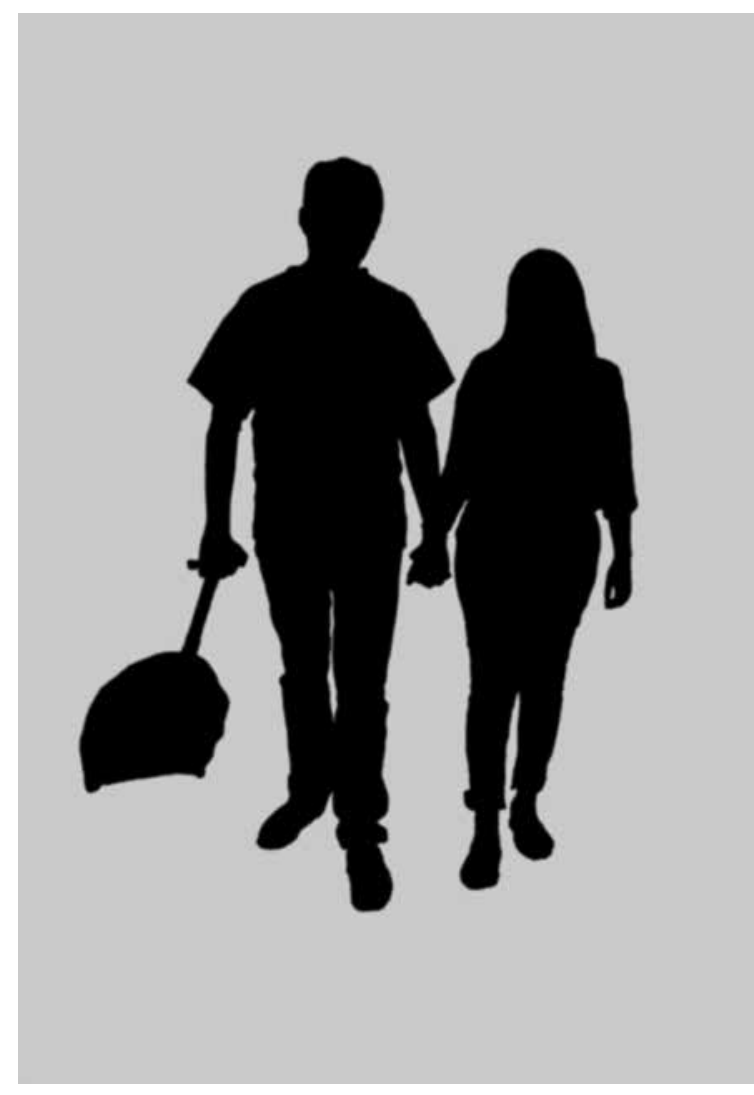

EduARdo Torre Cantalapiedra Migración por motivos conyugales. Tijuana, 2017.

es diversa. Aunque su padre lo animaba a observar a las chicas, narra que su atención estaba más centrada en el deporte que en las conquistas, incluso rechazaba invitaciones a fiestas. En suma, se autodefinía como "tímido":

Era bien chistoso que mi papá... Íbamos en la calle agarrados de la mano; cuando pasaba una chica guapa, me pulsaba la mano, así como de "¡eh, mira! Aquí viene una chica guapa", porque siempre me motivaba a ver a las chavas. Había varias niñas que me gustaban en la primaria, pero yo era bastante tímido, me daba pena hablar con esa niña que me gustaba (entrevista con Fernando, 29 de marzo de 2015). 
Sin embargo, esta idea negativa del noviazgo cambió en la universidad, cuando tenía 21 años de edad y empezó una relación amorosa con una extranjera poco mayor que él. Esta experiencia marcó un antes y un después en la vida de Fernando, pues tuvo que confrontar a su padre, quien no estaba de acuerdo con esa relación:

Ya en la universidad conocía un grupo de alemanes, los conocí bailando. Me hice amigo de una alemana y luego nos hicimos pareja y mi papá me prohibió hablarle [...], porque estaba acostumbrada a cosas diferentes, enfocada en la cuestión económica. Yo tenía 21 años, imagínate que tu papá te diga eso. Fue mi pareja durante cuatro años y mi papá no quería, y fue la primera vez que le dije: "oye, pues no me digas". Ya fue de confrontación con él, estaba bastante molesto, porque pensaba que yo me iba a quedar endeudado o iba a dejar los estudios por una chava, ése era el miedo, que no acabara la carrera. Pero no, [ella] me motivó a terminar la carrera, me abrió la mente a una relación diferente, era alemana y tres años más grande que yo (entrevista con Fernando, 29 de marzo de 2015).

Tiempo después de finalizar la relación, Fernando terminó la carrera y a los pocos días consiguió trabajo como ingeniero. A pesar de que no ejerció el papel de proveedor, que a esa edad no es una exigencia tan fuerte de la MH, podría señalarse que "ya cumplía" con el mandato, en la medida en que su buen desempeño laboral lo convertía en un buen proveedor en potencia.

La matriz de Collin (2007) no es exhaustiva, sino que hay aspectos y dimensiones que deben adaptarse o recuperarse en cada caso. Durante las entrevistas, emergieron dos cuestiones que ayudan de manera sobresaliente a entender la identidad masculina de Fernando, y por lo tanto, deben ser incluidas: 1) la relación con su padre, y 2) su perspectiva crítica con la división del trabajo extradoméstico y doméstico que establecieron sus progenitores.

Respecto a la relación que tenía con su padre, hay que señalar que estuvo marcada por el autoritarismo. No obstante, Fernando encuentra una contradicción entre las prácticas de su padre, que tiene como referente importante la $\mathrm{MH}$, y el hecho de que "siempre sí hacía quehaceres domésticos", que no concordaban con dicho referente. Además, su padre no hacía uso de la violencia física.

Un aspecto que consideramos crucial para entender su masculinidad como joven y joven-adulto es la percepción de Fernando sobre la relación de sus padres. La percepción es negativa, pues hasta hoy le causa conflicto y desaprueba las limitaciones laborales que su padre le imponía a su madre:

Siempre, estoy enojado siempre, me generó un tipo de situación bastante tensa y me genera mucho enojo, pero mucho. Eso sí no lo puedo superar y me preocupa mucho que mi mamá no se haya puesto las pilas. Oye, así de "no inventes", ahí sí me genera: “oye, mamá, ¿por qué no te defendiste?”, “oye, papá, no mames, ¿no?”. Ahí sí me genera mucha angustia y enojo, eso sí (entrevista con Fernando, 29 de marzo de 2015).

Estos episodios nos permiten entender la identidad de Fernando, su posicionamiento en relación con las formas alternativas de masculinidad, en particular en cuanto a papeles igualitarios en las relaciones de pareja. Se trata de momentos de negación y distanciamiento de las prácticas de la MH que enfrenta desde temprana edad: su convivencia con dos mujeres profesionistas, la toma de una postura más concreta y activa con la experiencia de su primera pareja, la confrontación directa con su padre, así como su actitud crítica respecto a la dominación de su padre sobre su madre. En suma, podemos inferir que la 
identidad masculina de Fernando se encuentra en un punto intermedio, ni duro ni blando, que al mismo tiempo es dinámico, crítico y reflexivo.

Antes de emprender el viaje a Estados Unidos, Fernando aún no cumplía los 30 años de edad y poseía el título de ingeniero. Dejó un trabajo para el que se requería alta calificación. Por su parte, Rose, de poco más de 30 años y nacionalidad estadounidense, había terminado la maestría y tenía un trabajo de acuerdo con sus calificaciones.

\section{La experiencia migratoria de Fernando y los malestares relacionados con los estereotipos del migrante y la masculinidad hegemónica}

\section{MIGRACIÓN POR AMOR}

El comienzo de su relación con Rose fue lento y hasta cierto punto inesperado. A pesar de la frecuencia con la que Fernando iba a su casa a tomar clases de inglés, le tomó tiempo enterarse de que ella se sentía atraída por él: "me tardé ocho meses en darme cuenta [de] que le gustaba [...], no me di cuenta de la cuestión de las señales, hasta meses después" (entrevista con Fernando, 13 de mayo de 2015). Una vez establecida la relación, pasaron de la inestabilidad a la formalización en poco tiempo: "fue muy claro que sólo íbamos a andar en lo que se regresaba, pero pues no fue así, nos seguíamos mandando mensajitos" (entrevista con Fernando, 13 de mayo de 2015).

En su último viaje a México, Rose le propuso a Fernando que se casaran. Ante la propuesta de matrimonio, ambos confeccionaron un plan — para "ver si la relación iba bien y luego tomar la decisión de si nos casábamos o no" (entrevista con Fernando, 13 de mayo de 2015) - . De acuerdo con el plan de la pareja, decidieron que Fernando emigrara a Estados Unidos por un periodo de seis meses para que pudieran convivir. Los motivos de esta decisión fueron que Rose quería estar cerca de su familia de origen y que Fernando deseaba aprender inglés, ingresar a una maestría y conocer a la familia de ella.

Desde la confección de este plan de pareja, empezó a construirse la particularidad de la migración de Fernando, pues su razón principal para emigrar era estar junto a su pareja y conocerla, con perspectivas de establecer una relación duradera. Esta situación colocó de inmediato a Fernando en una posición incómoda respecto a los preceptos de la $\mathrm{MH}$, pues de manera tradicional se espera que los hombres mexicanos emigren a Estados Unidos en búsqueda de un "mejor trabajo", y si lo hacen acompañados, es de una mujer que debe seguirlos de manera subordinada.

La postura de Fernando en cuanto a trabajar sin documentos fue clara desde un principio y la mantuvo hasta conseguir el permiso de trabajo legal:

\footnotetext{
No quise trabajar, yo pude trabajar de mesero en un bar o lo que sea, pero yo no quise ponerme en esa situación, porque yo llegué aquí por Rose, no por buscar trabajo, y también era una situación de orgullo, de "no rompo las leyes en México, no las rompo aquí”, y si Rose quiere estar conmigo pues así es la situación (entrevista con Fernando, 13 de mayo de 2015).
}

Para lograr vivir en Estados Unidos, Fernando y Rose crearon una estrategia de "supervivencia", en la que Fernando invirtió todos sus ahorros y vendió su automóvil para tener solvencia económica, aunque vivieran con austeridad. Por otro lado, Rose tomó el papel activo de administrar y planear los gastos del hogar: "ella es la administradora, lo que está en oferta, 'aquí está la lista de lo que tienes que comprar en tales tiendas, hay que hacer estas cosas en esta semana y vamos a hacer tal', ella es la que planea" (entrevista con Fernando, 13 de mayo de 2015).

Después de agotar los seis meses de estadía legal para turistas, Rose y Fernando decidieron 
asesorarse con abogados para conocer las mejores opciones legales para que él pudiese permanecer o volver a México y regresar después. Todos coincidieron en que lo mejor era casarse, pues el retorno de Fernando podría ser muy costoso. Ante esta situación, se casaron tres días antes de que expirara la visa. Una vez unidos, pasaron cuatro meses para que Fernando recibiera el permiso de trabajo oficial. Su discurso sobre la importancia de tener trabajo cambió, pues emplearse no era tan urgente entonces: "ya para diciembre, yo estaba ya con el permiso de trabajo y no empecé a buscar trabajo, porque estaba en los exámenes para certificación de inglés, entonces no quise presionar para buscar trabajo" (entrevista con Fernando, 13 de mayo de 2015).

Después de casi un año en Estados Unidos sin trabajar, el plan que confeccionó con Rose empezó a rendir frutos: Fernando obtuvo el certificado de inglés, y un poco más adelante, un empleo en el que pudo ejercer su profesión de ingeniero.

A lo largo del relato de la experiencia migratoria se observó que las acciones de Fernando divergieron de las esperadas según los mandatos de la MH. Con la emigración no buscaba cumplir con el papel de proveedor y realizaba tareas domésticas sin problema. En segundo lugar, no se comportaba de manera autónoma, como se "exige" al hombre en la MH, desde el momento en que hizo sus planes junto con Rose. Asimismo, no observó este mandato pues en ciertos momentos dependió del estatus de ciudadana de Rose, y cuando se terminaron los ahorros de su trabajo en México, ella tuvo que ser su sostén financiero por un tiempo. Por ello es probable que el tipo de migración de Fernando resulte

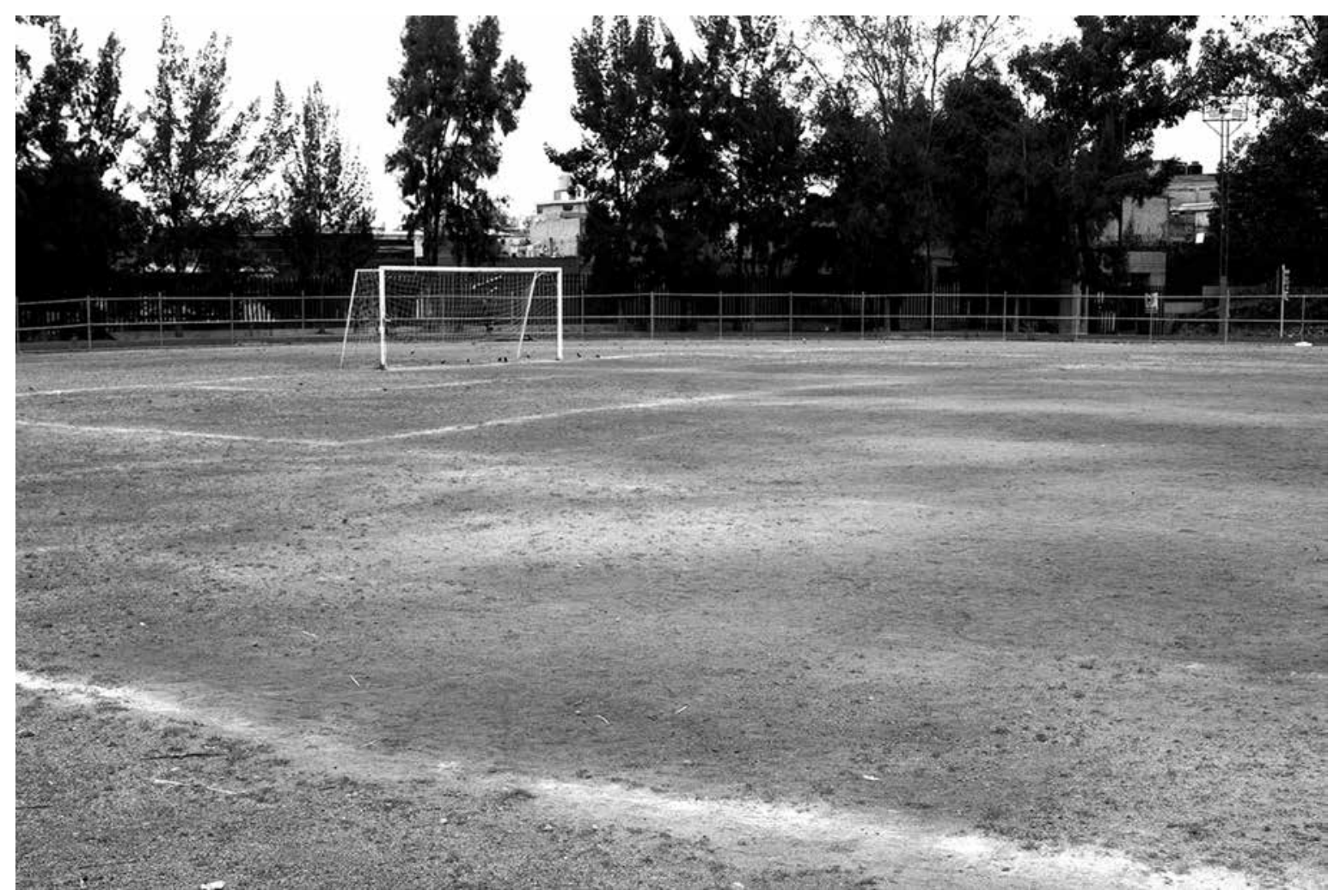

Eduardo Torre Cantalapiedra • La cancha de fútbol, espacio de reproducción social de la masculinidad. Ciudad de México, 2017. 
muy selectivo en cuanto al perfil de masculinidad del individuo, es decir, podemos esperar que aquellos con mayor apego al cumplimiento de los preceptos de la MH emprendan rara vez una movilidad de este tipo o al menos que no la lleven a cabo de la misma manera.

\section{Los malestares}

En la migración emprendida por Fernando, al no concordar con el estereotipo del migrante y no cumplir con los mandatos de la $\mathrm{MH}$, podrían producirse malestares derivados de tensiones y conflictos en su subjetividad, con su pareja, la familia y personas en su entorno social. A continuación, los presentaremos y analizaremos.

Dado que Fernando asume una masculinidad crítica, reflexiva y alternativa, alejado del referente hegemónico, el hecho de que su migración no se ajuste a los mandatos de la $\mathrm{MH}$ o al estereotipo del migrante trabajador no es per se una fuente de conflictos para su subjetividad. Así, la privación del trabajo extradoméstico y remunerado deja en él algunos sentimientos negativos, todos relacionados con el desarrollo de su carrera profesional, lo que deja al margen las interpretaciones hegemónicas de la masculinidad. Como se señaló, es justo su perfil de identidad masculina alternativa lo que lo hizo más propenso a emprender una migración de este tipo.

Esto no fue obstáculo para que en ciertos aspectos fuera él quien se presionara, conocedor de otros estereotipos asociados a los migrantes, en este caso respecto de aquellos que conviven con una persona con ciudadanía y la imposibilidad de abstraerse por completo de los mandatos de la $\mathrm{MH}$. Fernando no quería que la familia de Rose pensara que su migración era por la green card.

El dilema del estereotipo del que "sólo busca papeles" surgió de nuevo con la unión matrimonial. Para Fernando era molesta la interpretación de sus razones para contraer matrimonio con Rose de parte de quienes le rodeaban — familia, amigos y conocidos- Esto lo condujo a plantearse los motivos por los que se casaba: "sí, sabíamos que queríamos casarnos porque ya habíamos pasado el tiempo que nos habíamos propuesto, sí sentí la presión de 'híjole, ¿̇me estoy casando porque la quiero o por la visa?’” (entrevista con Fernando, 13 de mayo de 2015).

En contraste con lo anterior, varios malestares derivaron de conflictos surgidos en su relación con otras personas de su entorno, aunque no con su pareja. Una vez instalado en Estados Unidos, Fernando aprendió a convivir con Rose: "compartir el baño, la cocina, tuve que aprender a cocinar para ella, porque mi intención era estar aquî" (entrevista con Fernando, 13 de mayo de 2015). La situación de intercambio de papeles en las parejas se ha caracterizado por el surgimiento de conflictos (Kaztman, 1991). Por el contrario, en el caso de Fernando no se produjeron tensiones en la pareja durante la experiencia migratoria en la que durante un año él no realizó trabajo remunerado y se encargó del trabajo doméstico. Así se manifiesta la agencia del sujeto que permite tomar las tareas estigmatizadas por la $\mathrm{MH}$, consideradas exclusivas de las mujeres, e incluso bromear al respecto:

Durante todo el año yo hacía todos los quehaceres, de hecho yo tenía una broma, que yo era el desperate househusband, ${ }^{10}$ yo hago todo lo de la casa, cocino, voy al supermercado, todo lo hacía, me gustó cocinar, me latió, todo eso yo lo hacía, la cuestión de la casa yo lo hice por completo y cuando entré a trabajar ya fue 50-50, una semana ella cocina, una semana yo cocino; de hecho, yo voy a comprar siempre y ella es la administradora [...], soy el que

10 En alusión a la popular serie de la televisión estadounidense Desperate Housewives (Grossman et al., 2004-2012). 
hace muchas cosas y ya la cuestión de los roles de la casa está muy parejo (entrevista con Fernando, 13 de mayo de 2015).

Además, una vez que los recursos económicos de él se terminaron, ella se convirtió en la única proveedora del hogar, lo cual tampoco generó ningún tipo reclamo o conflicto que derivara en algún malestar. Cuando llegó el momento en que Fernando decidió buscar trabajo remunerado en su ramo, recibió el apoyo de Rose.

En cuanto a la esfera familiar, cuando los padres de Fernando se enteraron de su decisión de emigrar, comenzó la tensión entre la perspectiva de lo que "debe ser un hombre", encarnada de alguna manera por su familia, y lo que deseaba Fernando. El primer reclamo que le hizo su familia fue el abandono de la posición económica que había logrado: "la presión de la familia de: ‘qué vas a hacer seis meses allá?. Estaban preocupados por la cuestión económica. Si tenía un buen trabajo, ¿por qué me iba para allá?" (entrevista con Fernando, 13 de mayo de 2015). El trabajo, la autonomía que concede y la proveeduría, como ejes fundamentales de la vida de las personas, impiden entender cualquier decisión que superponga otras lógicas.

Además, el hecho de que Fernando emprendiera una migración tan alejada del estereotipo de inmigrante varón supuso que su padre no lograra darle sentido a su decisión. Para el padre, la migración es fruto de la necesidad de encontrar empleo que, en términos de masculinidades, implica la proveeduría: "había un tipo de prejuicio por parte de mi papá, de que [...] los mexicanos van a Estados Unidos para buscar un mejor trabajo, mejor vida, y en mi caso no era en ese panorama, sólo estar con Rose" (entrevista con Fernando, 13 de mayo de 2015). De otra manera, le atribuyen un estereotipo negativo: "un mexicano se casa con una güera porque nada más quiere tener la green card, 'sólo quieres estar con ella por eso'. Sí me afectó, eso me molestaba" (entrevista con Fernando, 13 de mayo de 2015).

En cuanto a la esfera social, el hecho de que el comportamiento migratorio de Fernando se alejara de lo esperado según los mandatos de la MH, como la proveeduría y el ser autónomo de la mujer, y que encarnara un esquema de inmigración distinto al estereotipo, produjo fricciones con el resto de los mexicanos que conoce en Estados Unidos, lo que a la postre le provocó un malestar. Estos hombres mexicanos sí han seguido una migración de tipo laboral, con las esposas detrás de ellos, y sus comportamientos concuerdan con el estereotipo del migrante y cumplen con los mandatos de la MH. La cuestión es narrada y analizada de manera crítica por Fernando:

[Las empresas] tienen necesidad de contratar ingenieros y los contratan en el extranjero. La mayoría de esos trabajos se lo dan a los ingenieros que son hombres, se les da papel; cuando te contrata una empresa, te dan visa de trabajo y te dan visa de residente para tu esposa y tu familia, entonces las esposas no pueden trabajar. Digamos que estuve en una situación similar, estaba como turista, pero con una relación, entonces mi esposa está trabajando y yo estoy con ella. Conocí a muchas mujeres de todo el mundo que vinieron por sus esposos y era bien interesante, porque estaba en la clase de inglés y había rusas, latinas, europeas, y decían: "mi esposo trabaja”, y decía yo: "pues yo estoy aquí con Rose para ver si la relación funciona". A todos se le hacía raro, ¿cómo y por qué un hombre mantenido por una mujer? No soportaban esa situación conmigo y no me hablaban, la sociedad era muy machista y no respeta a un hombre que es mantenido por su mujer, entonces no me ofendí, pero sí sentí esa línea de separación de: "nada más vienes de mantenido". Fíjate que hice muy buenos amigos, como tres o cuatro amigas, muy buenas, muy agradables, muy bien, nada de las demás o todos sus esposos me veían raro; mantenido por su novia, ¿qué 


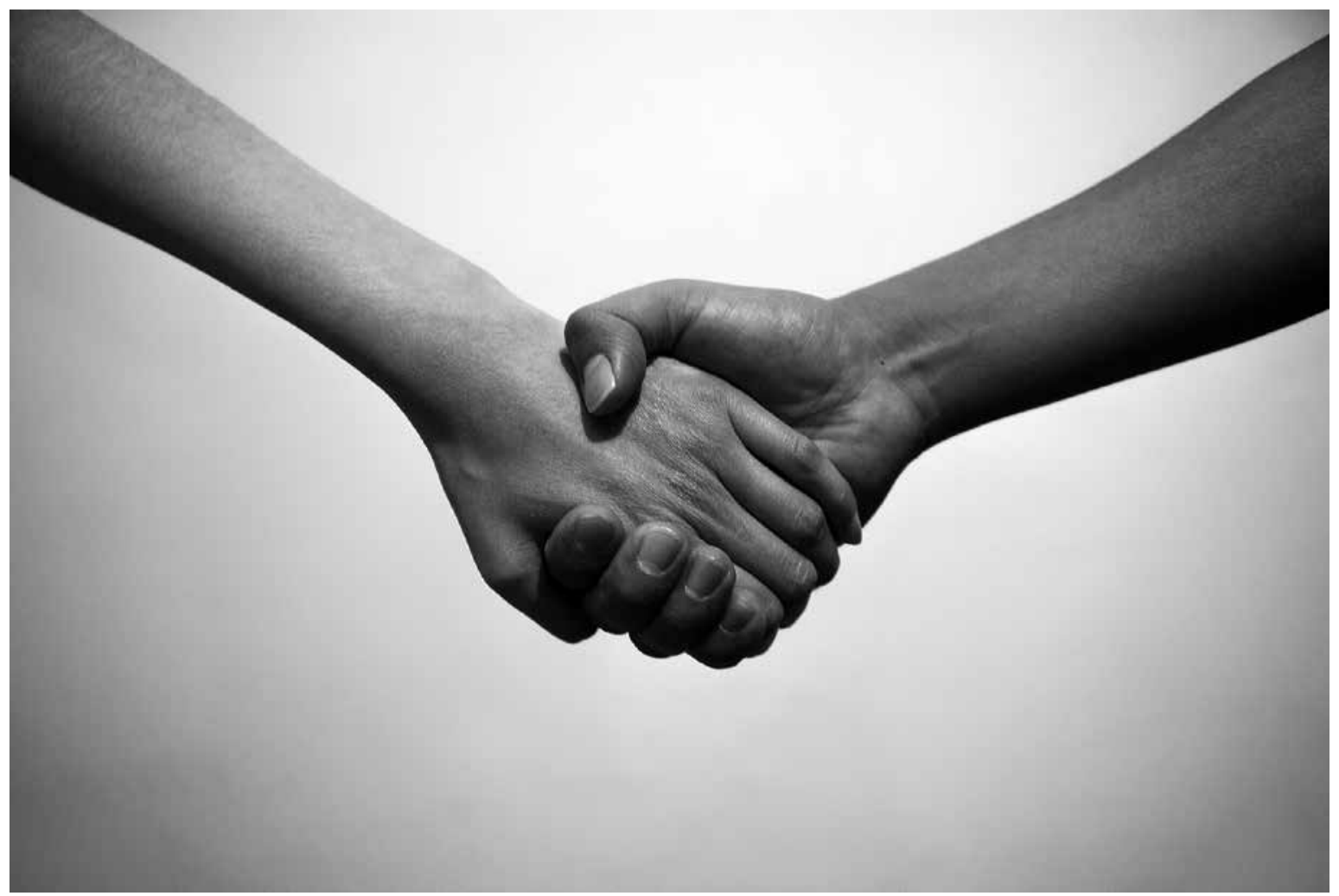

Eduardo Torre Cantalapiedra • La experiencia de emigrar por motivos conyugales. Ciudad de México, 2017.

tiene este wey, no? Esa situación sí me pegó, porque no pude hacer amigos hombres, siempre eran mujeres, bueno, pues haz amigas mujeres. Estuvo raro. Y pues sí, mucho mexicano, que también conocía sus esposas, con las clases de inglés, y sí, me hicieron sentir súper mal, "¿cómo un wey deja su trabajo para venirse a Estados Unidos para estar con su novia?”. Sí sentí feo de cómo me hicieron como bullying de "este wey aprovechado, nada más por la green card, no trabaja, es un huevón", es una persona de una universidad pública, a todos estos chicos los contrató Microsoft, vienen de una universidad privada, que llegaron con la mesa puesta, de aquí "hay trabajo, vente, está padre", y sí, híjole, sí me hicieron sentir mal. Entonces, ya les dejé de hablar, me alejé. Ahora, ya que tengo un buen de trabajo, todos los mexicanos que me criticaron me quieren hablar y ser mis amigos, pero dije "oye, compadre, pues no me hablaste cuando no tenía trabajo y me hiciste caca, pues ahí te ves" (entrevista con Fernando, 13 de mayo de 2015) [el subrayado es nuestro].

\section{Reflexiones finales}

El binomio masculinidad y migración es de importancia vital para el análisis de las masculinidades en un ámbito como el mexicano, dado que la inmigración ha sido la herramienta de muchos hombres mexicanos para cumplir de manera cabal con el mandato de proveer de la MH y seguir ostentando el poder. Como se analiza en este trabajo, existen otros tipos de migración que pueden servir para 
estudiar aspectos que incluyen las masculinidades alejadas de la MH y algunos estereotipos, que permiten comprender cómo algunas personas logran eludir la MH. Así, la migración funge como una lente magnificadora de los procesos sociales que nos permite, en este caso, observar con nitidez las prácticas e identidades masculinas no hegemónicas.

En este trabajo se ha analizado a profundidad el proceso de construcción de la identidad masculina de Fernando, un joven con determinadas características, como pertenecer a una generación y poseer un nivel de educación escolar, que tal vez le facilitaron adoptar una masculinidad alternativa en el contexto mexicano. En este sentido, observamos cómo el entrevistado se distancia de la MH de manera crítica y reflexiva a partir de sus experiencias vitales y decisiones, como el noviazgo con una joven inmigrante alemana y su posición contraria al control del padre sobre las esferas del mundo laboral a las que su madre podría acceder. La identidad masculina que su relato delinea por medio de sus vivencias pasadas pone en evidencia su actitud crítica con la MH y la profundidad de sus reflexiones en relación con lo que debe ser un hombre, y parece que lo compele a buscar una relación de pareja de carácter igualitario. Esta posición crítica hacia la MH no surge necesariamente de su educación escolar en cuanto a las cuestiones de género, sino de un proceso de aprendizaje que de algún modo estimula esta clase de cuestionamientos con base en sus experiencias.

Otros hallazgos sustantivos de esta investigación se refieren a las conexiones encontradas entre migración y masculinidad. Fernando decidió emprender un tipo de migración quizá muy selectiva respecto al perfil de masculinidad de quienes la realizan. Un hombre más cercano a la MH difícilmente hubiera hecho un viaje de tales características, que le impide trabajar. En la experiencia migratoria de Fernando no se cumplen los postulados tradicionales de la $\mathrm{MH}$ y del estereotipo del inmigrante, lo cual deriva en malestares con su familia y personas que conoce durante la experiencia migratoria. La migración de Fernando supone tensiones con sus familiares, que se sienten confundidos y la cuestionan, dada la existencia del estereotipo del inmigrante y la importancia de tener empleo seguro, pues aquí ya era autónomo y se le consideraba un óptimo proveedor en potencia. Es posible que gran parte de la explicación de este conflicto se deba a la cuestión generacional. Los valores de Fernando y de su padre difieren en la medida en que su socialización y formación educativa se produjeron en momentos muy diferentes en cuanto a los roles de género. Asimismo, hay una descalificación por parte de otros, que asumieron plenamente el papel que exige a los hombres la $\mathrm{MH}$, aun en su misma generación, lo cual genera ciertos malestares en él. D

\section{Bibliografía}

Badinter, Elisabeth, 1993, XY, la identidad masculina, Alianza, Madrid.

Bodoque Puerta, Yolanda y Montserrat Soronellas Masdéu, 2010, "Parejas en el espacio transnacional: Ios proyectos de mujeres que emigran por motivos conyugales", en Migraciones Internacionales, vol. 5, núm. 3, pp. 143-174.

Bonino, Luis, 2003, "Masculinidad hegemónica e identidad masculina”, en Dossiers Feministes, núm. 6, pp. 7-35.

Caicedo, Maritza y Agustín Morales Mena, 2015, Imaginarios de la migración internacional en México. Una mirada a los que se van y a los que llegan. Encuesta Nacional de Migración, Universidad Nacional Autónoma de México-Instituto de Investigaciones Jurídicas, México.

Capella Rodríguez, Santiago, 2007, “¿Sólo trabajadores/proveedores?”, en María Lucero Jiménez Guzmán y Olivia Tena Guerrero (eds.), Reflexiones sobre masculinidades y empleo, Universidad Nacional Autónoma de México-Centro Regional de Investigaciones Multidisciplinarias, Cuernavaca, pp. 153-180. 
Collin Harguindeguy, Laura, 2007, “Masculinidades diversas, aportes para su clasificación”, en María Lucero Jiménez Guzmán y Olivia Tena Guerrero (eds.), Reflexiones sobre masculinidades y empleo, Universidad Nacional Autónoma de México-Centro Regional de Investigaciones Multidisciplinarias, Cuernavaca, pp. 205-234.

Connell, Raewyn, 2003, Masculinidades, Universidad Nacional Autónoma de México-Programa Universitario de Estudios de Género, México. Figueroa, Juan Guillermo, 2001, “Los procesos educativos como recurso para cuestionar modelos hegemónicos masculinos”, en Diálogo y Debate de Cultura Política, año 4, núms. 15-16, pp. 7-32.

Figueroa, Juan Guillermo y Josefina Franzoni, 2011, "Del hombre proveedor al hombre emocional: construyendo nuevos significados de la masculinidad entre varones mexicanos", en Francisco Aguayo y Michelle Sadler (eds.), Masculinidades y políticas públicas. Involucrando hombres en la equidad de género, Universidad de Chile-Facultad de Ciencias Sociales, Santiago, pp. 64-81.

Gómez Solórzano, Marco Augusto, 2007, "Masculinidad en la sociedad de riesgo”, en María Lucero Jiménez Guzmán y Olivia Tena Guerrero (eds.), Reflexiones sobre masculinidades y empleo, Universidad Nacional Autónoma de México-Centro Regional de Investigaciones Multidisciplinarias, Cuernavaca, pp. 33-57.

Guba, Egon G. e Yvonna S. Lincoln, 1994, “Competing Paradigms in Qualitative Research”, en Norman Denzin e Yvonna S. Lincoln (eds.), Handbook of Qualitative Research, Sage Publications, Thousand Oaks, pp. 105-117.

Instituto Nacional de Estadística y Geografía (INEGI), 2010, Mapa nacional sin división política, Marco Geoestadístico Municipal 2010, versión 5.0, Instituto Nacional de Estadística y Geografía, México.

Kaufman, Michael, 1997, “Las experiencias contradictorias del poder entre los hombres”, en Teresa Valdés y José Olavarría (eds.), Masculinidad/ es. Poder y crisis, Facultad Latinoamericana de Ciencias Sociales-Chile/Isis International, Santiago, pp. 63-81.

Kaztman, Rubén, 1991, “¿Por qué los hombres son tan irresponsables?”, documento de trabajo, Taller de Trabajo "Familia, Desarrollo y Dinámica de Población en América Latina y el Caribe”, Comisión Económica para América Latina y el Caribe-Centro Latinoamericano y Caribeño de Demografía, Santiago.

Kimmel, Michael S., 1997, "Homofobia, temor, vergüenza y silencio en la identidad masculina”, en Teresa Valdés y José Olavarría (eds.), Masculinidad/es. Poder y crisis, Facultad Latinoamericana de Ciencias Sociales-Chile/Isis International, Santiago, pp. 49-62.

King, Russell, 2002, “Towards a New Map of European Migration”, en International Journal of Population Geography, vol. 8, núm. 2, pp. 89-106. McAdams, Dan P., 2011, "Narrative Identity”, en Seth J. Schwartz, Koen Luyckx y Vivian L. Vignoles (eds.), Handbook of Identity Theory and Research, Springer, Nueva York, pp. 99-115.

Núñez Noriega, Guillermo, 2013, Hombres sonorenses. Un estudio de género de tres generaciones, Universidad de Sonora/Pearson Educación, Hermosillo.

Olavarría, José, 2002, "Hombres: identidades, relaciones de género y conflictos entre trabajo y familia”, en José Olavarría y Catalina Céspedes (eds.), Trabajo y familia: ¿conciliación? Seminario-taller: Estrategias de conciliación, familia y trabajo con perspectiva de género, Servicio Nacional de la Mujer/Facultad Latinoamericana de Ciencias Sociales-Chile/Centro de Estudios de la Mujer, Santiago, pp. 53-76. 2003, “Los estudios sobre masculinidades en América Latina. Un punto de vista”, en Anuario Social y Político de América Latina y el Caribe, núm. 6, pp. 91-98.

Parrini, Rodrigo, 2000, “Apuntes acerca de los estudios de masculinidad. De la hegemonía a la pluralidad”, en Red de Masculinidad. Disponible en línea: <http://www.eurosur.org/FLACSO/apuntesmasc.htm>.

Perraudin, Anna, 2014, "Migrar para afianzar las masculinidades. La renegociación de las relaciones de género de la ciudad de México a los Estados Unidos: el caso de una población indígena”, en María Eugenia Zavala de Cosío y Virginie Rozée (coords.), El género en movimiento. Familia y migraciones, El Colegio de México, México, pp. 333-357.

Ponce, Patricia, 2004, “Masculinidades diversas”, en Desacatos. Revista de Antropología Social, núms. 15-16, pp. 7-9.

Roca Girona, Jordi, 2007, “Migrantes por amor. La búsqueda y formación de parejas transnacionales”, en AlBR, Revista de Antropología, vol. 2, núm. 3, pp. 430-458.

Rondán Vásquez, Luis, 2015, “¿Construyendo una masculinidad 'alternativa' desde la escuela peruana? Una aproximación a la socialización masculina del joven en un colegio limeño de orientación alternativa", en Debates en Sociología, núm. 41, pp. 103-131.

Rosas, Carolina, 2008, Varones al son de la migración. Migración internacional y masculinidades de Veracruz a Chicago, El Colegio de México, México. 
__ 2014, "¿Cómo se toman las decisiones en el hogar? Cambios y continuidades en las voces de mujeres y varones peruanos en Buenos Aires", en María Eugenia Zavala de Cosío y Virginie Rozée (coords.), El género en movimiento. Familia y migraciones, El Colegio de México, México, pp. 295-331.

Sancho, Juana M., Fernando Hernández, Fernando Herraiz y Judit Vidiella, 2009, "Una investigación narrativa en torno al aprendizaje de las masculinidades en las escuelas”, en Revista Mexicana de Investigación Educativa, vol. 14, núm. 43, pp. 1155-1189.

Schongut Grollmus, Nicolas, 2012, "La construcción social de la masculinidad: poder, hegemonía y violencia", en Psicología, Conocimiento y Sociedad, vol. 2, núm. 2, pp. 27-65.

Shah, Alpa, 2006, "The Labour of Love: Seasonal Migration from Jharkhand to the Brick Kilns of Other States in India", en Contributions to Indian Sociology, vol. 40, núm. 1, pp. 91-118.

Sinke, Suzanne, 1999, "Migration for Labor, Migration for Love: Marriage and Family Formation across Borders", en OAH Magazine of History, vol. 14, núm. 1, pp. 17-21.

Tena Guerrero, Olivia, 2014, “Malestares laborales y condición masculina. Reflexiones en torno a la 'flexibilidad laboral'”, en Juan Guillermo Figueroa (coord.), Políticas públicas y la experiencia de ser hombre. Paternidad, espacios laborales, salud y educación, El Colegio de México, México, pp. 51-78.

Tovar-Hernández, Deysy Margarita y Tania Esmeralda Rocha Sánchez, 2012, "Masculinidades: espacios-momentos críticos en las formas de ser hombre en la Ciudad de México", en Psicología Iberoamericana, vol. 20, núm. 2, pp. 9-17.

Woo Morales, Ofelia, 1995, “La invisibilidad en el proceso migratorio: las mujeres migrantes”, en Frontera Norte, vol. 7, núm. 13, pp. $139-148$.

\section{Filmografía}

Grossman, Larry et al. (dirs.), 2004-2012, Desperate Housewives, serie de televisión, Cherry Alley Productions/Cherry Productions/Touchstone Television/ABC Studios, California.

\section{Entrevistas}

Fernando, 29 de marzo de 2015, 13 de mayo de 2015 y 15 de noviembre de 2015.

Rose, 15 de noviembre de 2015 